MEMÓRIA

\title{
História da Pesquisa e Desenvolvimento na Bahia: vicissitudes e conquistas
}

\author{
Amilcar Baiardi \\ Professor titular da Universidade Federal do Recôncavo da Bahia e professor permanente do Programa de Pós- \\ Graduação em Ensino, Filosofia e História da Ciência da Universidade Federal da Bahia e da Universidade Estadual \\ de Feira de Santana
}

\section{Do Imperial Instituto Bahiano de Agricultura para o Instituto de Química Agrícola e Tecnologia da Bahia e deste para o Instituto de Tecnologia da Bahia}

O início das atividades técnico-científicas do Imperial Instituto Bahiano de Agricultura - IIBA se deu em 1875, mas a abertura oficial do ensino das ciências agrárias só veio a acontecer em 15 de fevereiro de 1877, com o início dos cursos de engenharia agronômica e medicina veterinária. O IIBA foi pioneiro como arranjo de sustentação, pois contava com recursos da "Coroa" por meio de doaçōes regulares de D. Pedro II, com financiamento da Província da Bahia via recursos orçamentários e com contribuiçōes do setor produtivo, no caso os produtores de açúcar, proprietários de engenhos. Nesta primeira fase, o IIBA possuía 17 professores, a maioria constituída por brasileiros. A instituição oferecia, ainda, cursos técnicos, inclusive o de gerente florestal. Para conclusão dos cursos superiores era exigida a defesa de tese. O IIBA encerrou suas atividades de ensino superior em 1904, já com o nome de Instituto Bahiano de Agricultura - IBA, em virtude do advento da República, havendo formado 273 engenheiros agrônomos, ${ }^{1}$ uma vez que o curso de veterinária não se consolidou.

1 Como era de se esperar, a maior parte dos que se graduaram em agronomia pertencia à elite baiana, sendo que parcela significativa tinha sobrenome relacionado com a aristocracia agrária. 
A participação dos donos de engenho de açúcar como mantenedores do IIBA, na forma de pagamento de uma taxa por arroba produzida, desaparecera há mais de uma década. Como a instituição não tinha vinculação orgânica com o Estado, nem na esfera federal nem provincial, os problemas de manutenção se agravaram, ameaçando sua sobrevivência e desfazendo o modelo tripartite, de parceria entre o Estado, em seus dois níveis, e os produtores de açúcar (FIÚZA, 1934; GUIMARÃES, 1934, p. 36).

Neste mesmo ano, 1904, o Estado da Bahia decidiu assumir integralmente a instituição, entregando seu destino a pesquisadores de nacionalidade europeia. Diante do grande prestígio da ciência germânica, em sua proposta da geografia da hegemonia da produção do conhecimento, Yusa (apud BAIARDI, 1996) define o período de 1810 a 1920 como sendo de inquestionável hegemonia da ciência germânica - foram contratados três agrônomos alemães, Leo Zehutner, Julius Lohmman e Edmund Schubert, como professores e pesquisadores do IBA.

A liderança da nova instituição foi confiada ao pesquisador Leo Zehutner, que vinha trabalhando com agricultura tropical na ilha de Java. Em sua primeira manifestação oficial, o pesquisador alemão condenou o ensino agronômico que se conduzira no IBA, taxando-o como excessivamente teórico, voltado para a formação de "bacharéis", que estavam mais interessados em empregos públicos do que em dedicar-se à agricultura. $\mathrm{O}$ reduzidíssimo número de engenheiros agrônomos que, após a graduação no IIBA e no IBA, foram conduzir atividades nas fazendas do Recôncavo da Bahia ou de outras regióes do Estado era, para Leo Zehutner, um indicador de que o curso de agronomia deveria suspender seu funcionamento até que houvesse uma grande produção científica e técnica no Instituto. Segundo Baiardi (1996), a visão de Zehutner era uma consequência do que vinha acontecendo na Alemanha desde meados do século XIX, com o modelo de ensino superior vinculado à pesquisa.

A direção de Leo Zehutner, que durou seis anos, atraiu outros pesquisadores estrangeiros. Neste período vieram da Europa Ph von Schultzeburg, Paul Bigler, Paul Huart Chevalier, Zolinger e Charles Reginald Girdwood.

Em que pese sua grande dedicação, Leo Zehutner não obteve o apoio que necessitava para manter uma instituição científica nos padrões que ele exigia e o IBA encerrou definitivamente suas atividades em 1911. O acervo foi então passado ao governo federal, que o utilizou para a instalação da Escola Média Theórico-Práctica de Agricultura, que também teve vida efêmera. O majestoso edifício que foi sede do IIBA, localizado em São Bento das Lages e hoje distrito de São Francisco do 
Conde, voltou a sediar novas atividades somente em 1920, quando o Estado da Bahia, mais uma vez, assumiu o acervo e recriou o curso de agronomia por meio da Eschola Agrícola, que, a partir de 1930, foi transferida para Salvador, para a antiga Hospedaria dos Imigrantes de Mont Serrat.

Um balanço cobrindo o período de 1875 a 1911 - os 36 anos de maior atividade - indica que o IIBA produziu um rico acervo de conhecimentos técnicocientíficos, contribuindo para a expansão e consolidação no Recôncavo Baiano e adjacências das lavouras da cana-de-açúcar, do fumo, do café ${ }^{2}$ e do algodão - estas tipicamente de exportação - e as lavouras da mandioca e outros tubérculos e raízes, fruteiras, legumes diversos, bem como atividades de produção animal, voltadas majoritariamente para o mercado interno. Para estas atividades, o IIBA contava com estações experimentais e laboratórios nos quais se realizavam numerosas investigações que levaram a resultados e inovações que foram incorporadas tanto nas atividades agroaçucareiras e fumageiras - que juntas respondiam por quase $1 / 4$ de todas as exportações do Estado na primeira década do século XX - como naquelas de abastecimento interno.

No caso da atividade agro-sucro-alcooleira, é também provável que as iniciativas dos produtores de melhorar a performance dos canaviais e dos engenhos, a partir de introdução de variedades de cana provenientes das ilhas Maurícias e de novas técnicas de produção industrial provenientes da Luiziana, tenham tido alguma intermediação do IIBA. O mesmo pode ter ocorrido quando, na segunda metade do século XIX, as usinas começaram a substituir os engenhos, graças à generalização do emprego do vapor no processo produtivo. Esta difusão permitiu que fossem introduzidas técnicas como o cozimento a vácuo e a turbinação da massa cozida. Em 1875, dos 839 engenhos localizados na Bahia, 282 eram a vapor. Este ambiente de mudança foi acompanhado da construção de uma malha ferroviária no Recôncavo e de uma rede interna de ferrovias, processo esse associado com a concentração de terra e de produção de açúcar e álcool e ensejado pelos engenhos que conseguiram diferenciar-se. Aos demais, foi reservado o papel de fornecedores de cana.

No caso do abastecimento interno - que era um problema grave, como sugere a circular de 1857 enviada pelo presidente do Conselho de Ministros, o marquês de Olinda, para todos os presidentes das províncias solicitando que respondessem cinco perguntas $^{3}$ sobre as causas da carestia -, há indícios de que o IIBA teria melhorado a

2 Além do Recôncavo, o café era produzido em outras regiões. Uma colônia de lavradores suíços e alemães, fundada em 1818, chegou a produzir em Caravelas, extremo sul do Estado, 70.00 arrobas (AGUIAR, 1960).

3 O presidente da Província da Bahia, Conselheiro Herculano Ferreira Penna, informou ao Governo Geral que a causa da carestia era a escassez de escravos. 
base técnica dos sistemas produtivos que se organizavam fora do modelo do engenho, os quais produziam fumo e se dedicavam também à produção de gêneros alimentícios. Essa agricultura tinha como base a pequena produção patrimonial-escravista, que utilizava até três escravos e mais a mão de obra familiar e a estritamente familiar.

A influência das atividades do IIBA fora do Recôncavo Baiano certamente foi uma realidade. Obviamente que não foram beneficiadas pela atuação da instituição aquelas áreas de produção animal e cotonífera localizadas no Norte, Centro-Oeste e Sudeste, que se encontravam polarizadas por Pernambuco e Minas Gerais; no caso do algodão, vendia-se toda a fibra colhida para as indústrias de tecelagem de Minas Gerais. As áreas de produção localizadas no litoral sul e no agreste, ao norte do Recôncavo, produtoras de açúcar, cacau, fumo, café, chá, mandioca, feijão e outros cereais e de criação de bovinos e ovinos, foram em alguma medida beneficiadas, seja pela ação direta do IIBA em termos de assistência técnica, seja pela ação indireta de propagação de conhecimentos e de difusão de espécies e variedades de plantas e animais.

É notório que o IIBA, como centro de pesquisas e escola de agronomia, além da mais de uma centena de teses de fim de curso cobrindo os mais variados aspectos da agricultura baiana e brasileira, introduziu e adaptou ainda um grande número de fruteiras, gerando e difundindo conhecimentos que não se restringiram às técnicas dos cultivares que se destacavam pela capacidade de serem bens comercializáveis. Os benefícios de sua criação não podem ser avaliados, exclusivamente, por uma provável contribuição direta na expansão e consolidação no Recôncavo Baiano das lavouras de cana-de-açúcar e fumo, tipicamente de exportação. Estes se deram também em termos de diversificação dos sistemas produtivos, sobretudo os formados com outras lavouras de consumo interno, bem como com a fruticultura e a produção animal, possibilitando a complexificação da atividade rural e o funcionamento do recôncavo como área de abastecimento de inúmeras cidades, sobretudo da capital da Província, dando sustentação a uma relação idealizada de cidade mercantil com região agrícola, a qual foi parte do grande projeto internacional açucareiro, comandado por interesses judaicos ramificados em Portugal, Itália e Holanda e voltados para o Brasil após o descobrimento (BAIARDI, 1999 e 2001).

Com a decisão de transferir em 1944 a Escola Agrícola para o município de Cruz das Almas, já então com o nome de Escola Agronômica da Bahia, não mais de onde fora criada, mas sim de Salvador, para onde fora transferida em 1930, o governo estadual decidiu manter na capital do Estado parte do acervo bibliográfico, da infraestrutura de pesquisa e dos recursos humanos dessa instituição e, com essa 
base, criou na mesma edificação o Instituto de Química Agrícola e Tecnologia da Bahia, por meio do Decreto-Lei no 658, de 16 de novembro de 1945 . A nova instituição não teve grande destaque na geração de inovações para o setor produtivo, apresentando um perfil mais próximo a órgão público encarregado de realizar análises e perícias. Além disso, carregava na sua imagem a herança da Escola Agrícola, uma vez que se definia como instituição de química agrícola.

Provavelmente por razôes de imagem profissional dos pesquisadores que ingressaram após a criação ou talvez na esperança de poder vir a colaborar com outros setores produtivos e com um novo ciclo de desenvolvimento da Bahia - convém lembrar que as notícias sobre ocorrência de petróleo na Bahia criavam então expectativas de um importante papel a ser desempenhado pelas pesquisas em química industrial -, o governo, por meio da Lei n. 153 de 30 de dezembro de 1948, transformou o então Instituto de Química Agrícola e Tecnologia da Bahia em Instituto de Tecnologia da Bahia, cuja missão seria:

[...] entidade autônoma, com personalidade juridica, administração e patrimônio próprio, com sede e foro em Salvador, tendo por fim: 10) Estudar as matérias primas e os produtos industrializados, especialmente os bahianos, no sentido de seu melhor conhecimento e aplicação; 2o) Auxiliar, dentro de suas especialidades, a formação de técnicos para o fomento às atividades industriais e agricolas; 30) Realizar pesquisas capazes de interessar às atividades industriais e agricolas, principalmente as bahianas $\left.e ; 4^{\circ}\right)$ Estimular e incentivar os poderes públicos, os centros industriais e agrícolas e as empresas particulares, à realização de estudos e pesquisas que the interessem indiretamente. (www. bahia.ba.gov.br/segovdown/Leis, acesso em janeiro de 2012).

Malgrado no início dos anos 1970 a Bahia estar vivendo o quarto ciclo ou impulso industrializante, ${ }^{4}$ a interação do Instituto de Tecnologia com o setor produtivo - a indústria baiana - era muito frágil, devido basicamente a uma cultura empresarial não valorizadora do risco da $\mathrm{P} \& \mathrm{D}$ com vistas a gerar inovação. Por outro lado, o Instituto de Tecnologia da Bahia, durante sua existência como órgão da administração pública indireta, não teve flexibilidade de captar recursos, contratar pesquisadores novos e remunerá-los de acordo com o mercado, o que levou à sua estagnação. Com a Bahia beneficiando-se de políticas industriais e dos mecanismos de incentivos fiscais da Superintendência do Desenvolvimento do Nordeste (Sudene) - o dispositivo 3.418, depois convertido no Fundo de Incentivo à Industrialização

4 Uma breve história dos impulsos industrializantes da Bahia pode ser encontrada em Baiardi e Vieira dos Santos (2010). 
do Nordeste (FINOR) -, decidiu-se por um arranjo organizacional mais adequado aos novos tempos, criando-se o Ceped (BAIARDI; BASTOS, 2007, p. 9).

\section{0 nascimento do Ceped}

O Centro de Pesquisa e Desenvolvimento - Ceped foi criado pelo Decreto n. 21.913, de 08 de julho de 1970 e sua existência marcou o período áureo na história da P\&D na Bahia. Nasceu inicialmente como uma fundação vinculada à Secretaria de Ciência e Tecnologia, sendo, posteriormente, integrado à Secretaria do Planejamento como administração indireta. A criação do Ceped pode ser considerada a ação mais marcante, naquele período, do governo estadual na área de Ciência e Tecnologia - C\&T.

A missão do Ceped era gerar inovaçóes tecnológicas por meio de desenvolvimento e aperfeiçoamento de produtos e processos e prestar serviços tecnológicos utilizando a área de laboratórios básicos. O Centro nasceu com amplo espectro de atuação, abrangendo áreas de tecnologia agroindustrial, tecnologia da indústria química, tecnologia ambiental, tecnologia mineral, tecnologia dos materiais, tecnologia habitacional, tecnologia de energia alternativa, engenharia civil; documentação e informação e desenvolvimento de recursos organizacionais.

Essa capacidade de atuação conferida ao Ceped foi favorecida por volumosos recursos investidos, oriundos de agências internacionais, como BID, OEC, ONU e FAO, agências nacionais, como Banco do Brasil, BNB, Sudene, Finep, além da SDI (Secretaria de Desenvolvimento Industrial do MIC), que estimularam a construção de uma capacidade em equipamentos e um know how nunca antes presenciado no Estado. A capacidade científica e tecnológica instalada no Ceped proporcionou um suporte na viabilização de projetos importantes para o período, tanto na Bahia como em outros Estados, entre os quais destacam-se: processamento de minérios da Caraíba Metais; nacionalização de peças importadas do Polo Petroquímico e Petrobras; controle de qualidade de produtos e materiais da barragem Pedra do Cavalo e Desenvale; soluçôes para os rejeitos industriais de empresas e organizações, como a Urbis, OAS, CRA; desenvolvimento de metodologia analítica e de controle de qualidade do Polo Petroquímico, CRA, CETREL, Petrobras, Xérox do Brasil e White Martins;análises de impacto ambiental do CRA e Cetrel; tecnologia simplificada de construção de baixo custo do $\mathrm{BNH}$, CEF e prefeituras; desenvolvimento de equipamentos para processamento de dendê e sisal; apoio a demandas tecnológicas nas áreas de petroquímica e de síntese de produtos químicos, abrangendo catálise, 
separação de misturas e polímeros, fruto de um convênio com o COFIC; assistência à necessidade de refino de ouro da Casa da Moeda; e planos de desenvolvimento agroindustrial para Estados do Nordeste, com apoio do BNB e de Secretarias de Indústria e Comércio (NUNES, 1993).

$\mathrm{Na}$ linha de qualificação do Ceped e com a intenção de criar melhores mecanismos de articulação com o setor produtivo, foi implantado, em 1984, o Núcleo de Inovação Tecnológica - NIT, participando da rede nacional de Núcleos de Inovação Tecnológica por meio de um convênio firmado com a Financiadora de Estudos e Projetos - Finep e com a intervenção do Conselho Nacional de Desenvolvimento Científico e Tecnológico - CNPq.

\section{Impulsos e vicissitudes no apoio aos centros de pesquisa tecnológica no Brasil nas décadas de 1970 e 1980}

Somente a partir dos estudos de Schmookler (1966 e 1979) e da OCDE (1971) sobre o desempenho da economia norte-americana no pós-Segunda Guerra Mundial e sobre a relação entre investimentos em P\&D e crescimento econômico, houve consenso entre as diferentes vertentes do pensamento econômico quanto à importância da mudança tecnológica como impulsionadora do crescimento econômico. Este fato influenciou as teorias de desenvolvimento econômico, que passaram a associar o crescimento da economia e a industrialização a uma maior renovação da base tecnológica, a qual poderia se dar tanto pela via da importação/adaptação de tecnologia como pela geração autóctone do conhecimento.

No caso brasileiro já vinha se dando uma renovação da base tecnológica com impactos inequívocos sobre o desempenho da economia. De acordo com Suzigan e Albuquerque (2009), no caso específico do Brasil, estudos recentes mostram que as raízes históricas do sistema de inovação datam de um longo prazo de interação entre instituições de pesquisas e universidades, de um lado, e empresas industriais, produtores agrícolas e sociedade, de outro. Provavelmente esta percepção fez com que os principais policy makers do ciclo de governantes militares passassem a conceber a importância da C\&T não somente para converter o Brasil em uma potência econômica e militar, mas também para promover o desenvolvimento econômico.

A partir dos anos 1970, o planejamento macroeconômico começou a associar a política industrial com a política de ciência e tecnologia. Além disso, agregou-se a visão de que a industrialização descentralizada funcionaria como mecanismo de redução das desigualdades regionais. Estavam aí, então, todos os ingredientes de 
um programa de formação de rede de centros de pesquisa e desenvolvimento, que se distribuiriam por todas as regiôes do Brasil. O Plano de Metas e Bases para a Ação do Governo no Período 1970/71 promoveu esta articulação. A Finep, recentemente criada como empresa pública, passou a ser Secretaria Executiva do Fundo Nacional de Desenvolvimento Científico e Tecnológico - FNDCT e deu-se início ao planejamento em C\&T, que nas três versōes do Plano Básico de Desenvolvimento Científico e Tecnológico - os PBDCTs - passou a contemplar esta proposta, definindo objetivos e metas (MOTOYAMA et al., 1994). Com isso, passou-se a ter o marco político, de planejamento e regulatório de criação de centros de P\&D por unidades da federação.

Autores como Donadio (1983), Motoyama (1994), Cassiolato (1983) e Schwartzman (1995) são unânimes em reconhecer que estas medidas inauguraram um período áureo, de deslumbramento, com as possibilidades de geração de $\mathrm{P} \& \mathrm{D}$ autoctonamente e que por isso não faltaram recursos aos institutos de pesquisa tecnológica durante grande parte da década de 1970. De acordo com Ferrari (1978), foi também nesta década que se organizou o Sistema Brasileiro de Ciência e Tecnologia e examinaram-se "as vantagens relativas de importação versus geração de tecnologia”, o que impulsionou a visão de integrar o desenvolvimento científico com o tecnológico e com a renovação da base tecnológica do parque industrial brasileiro.

De acordo com Schwartzman (1995), o que de certo modo já havia sido anunciado por Cassiolato (1983), os anos 1980 foram de grande instabilidade e incerteza para a ciência e a tecnologia e só se percebem incrementos nos dispêndios em C\&T no início dá década, em função de financiamentos com suporte do Banco Mundial como o PADCT, e após 1986, por conta do Plano Cruzado e pelo prestígio que a área adquiriu no início da Nova República, tendo Renato Archer como ministro de Ciência e Tecnologia e Luciano Coutinho como secretário geral do Ministério. Em 1985, o FNDCT em termos reais era $1 / 4$ do que fora em 1979. Este quadro de dificuldades perdurou na década de 1990, constituindo-se em verdadeiro retrocesso nas condiçôes de financiamento pelo Estado das atividades de $\mathrm{P} \& \mathrm{D}$ em institutos públicos de pesquisa tecnológica

As causas deste quadro de involução e retrocesso na pesquisa aplicada e na P\&D realizadas em instituições mantidas pelas unidades federadas fazem parte de uma situação generalizada de crise fiscal da República. Durante a vigência desta crise, algumas funçôes de governo tidas como de resposta de médio prazo ou passíveis de financiamento pelo setor produtivo - como a geração de conhecimento aplicado e a $\mathrm{P} \& \mathrm{D}$ - foram consideradas não prioritárias diante de outros itens do gasto público. 
Assim, instaurou-se por cerca de dez anos, nas instituiçóes de pesquisa mantidas pelo setor público, um circulo vicioso, no qual as dificuldades de manutenção, os baixos investimentos em renovação da infraestrutura e redução de estímulos à formação científico-tecnológica repercutiram na frágil captação de recursos externos, os quais condicionaram uma elevada dependência em relação ao orçamento do Estado como unidade federada que, por sua vez, determinou pressões por redução das despesas com pessoal, gerando desestímulo e baixa produção e terminando por incidir negativamente na formação dos pesquisadores. Após a Constituição de 1988, o imperativo de menor dependência de recursos da União era parte das diretrizes emanadas do Sistema Nacional de Desenvolvimento Científico e Tecnológico - SNDCT. Neste sentido, os Estados deveriam começar a responder, cada vez mais, por funções antes exclusivas da órbita federal, em razão das novas regras de repartição da arrecadação dos principais impostos e taxas recolhidos pela União, o pacto federativo no concernente à questão fisNesta conjuntura de dificuldades, graças às políticas agressivas de geração de recursos próprios, redução do espectro temático de P\&D e maior articulação com o setor produtivo, alguns centros de $\mathrm{P} \& \mathrm{D}$ públicos conseguiram manter massa crítica e, em poucos casos, até expandir-se, como o Itep e Tecpar, o que não foi o caso do Ceped, segundo Baiardi (1991 e 1992).

Na transição dos anos 1990 para a primeira década de 2000, a alvissareira notícia da criação dos fundos setoriais, vistos como imaginosa concepção para aumentar a dotação de C\&T sem sobrecarregar o Tesouro, deu novo ânimo à comunidade científica estadual. A maneira como foi operado o fundo pioneiro, o CTPetro, destinando parte dos recursos à emulação das comunidades das regióes periféricas, imprimiu mais otimismo, reforçado ainda pelos editais do CNPq e Finep, restabelecendo o fluxo de financiamento à pesquisa a fundo perdido e a re-dinamização do FNDCT. Na Bahia, este quadro mais favorável foi acompanhado pela criação da Secretaria de Ciência, Tecnologia e Inovação - Secti e da Fundação de Apoio à Pesquisa da Bahia - Fapesb. Esta nova conjuntura, entretanto, chegou tarde, pois o Ceped, após uma longa "sangria" de seus recursos humanos, foi extinto em 1999 como ente autônomo, com transferência dos seus ativos para a Universidade do Estado da Bahia - Uneb.

\section{A trajetória da P\&D na Bahia pós-Ceped}

O esforço de endogeneizar a produção do conhecimento necessário à geração de inovações de processo e de produto sugere uma tendência evidente, pelo menos nesta 
passagem de século, na direção da crescente contribuição dos centros de pesquisa relacionados com a produção científica e com os avanços tecnológicos e, antes de tudo, pela disponibilização de recursos em $\mathrm{P} \& \mathrm{D}$ por parte das grandes corporações. Esta visão, tipicamente shumpeteriana, é questionada por alguns estudiosos que sustentam que uma grande porcentagem de inovação é ainda atribuída aos inventores privados (DOSI, 1984). Independentemente da importância que tenha a segunda visão, o problema crucial, entretanto, ainda permanece e se explicita melhor com a seguinte pergunta: como pode a Bahia ampliar as condiçóes de competitividade, potencializar inovaçôes transformadoras na base produtiva do Estado e gerar oportunidades para um novo salto de desenvolvimento baseado nas tendências tecnológicas recentes? Esta pergunta se coloca no quadro da discutível capacidade do Estado, como periferia da periferia em termos de produção científica, de elevar sua capacidade de geração de conhecimento a um nível de funcionalidade necessário ao relacionamento pesquisa-produção ou ciência-tecnologia-produção. Obviamente que alguns segmentos produtivos têm mais vantagens comparativamente a outros, seja pela natureza estruturante, seja pela maior capacidade de utilizar potencialidades de uma base científica e tecnológica representativa em termos regionais e ampliar sua competitividade com base em inovações tecnológicas. Entretanto, este é um quadro restrito.

Em dois estudos recentes (RIBEIRO, 2004a e 2004b) fica evidente o quanto se tem que avançar na Bahia por parte dos vários atores institucionais, em termos de melhor conhecimento da capacidade de produzir ciência básica e realizar P\&D e o quanto deve haver de esforço público e privado para colocar esta capacidade em condições de interagir mais diretamente com o setor produtivo. Quando se pensa na capacidade de realizar pesquisa básica e aplicada, verifica-se que no âmbito da unidade da federação os grupos mais consolidados, inseridos na Universidade Federal da Bahia, na Fundação Gonçalo Muniz e no Centro Nacional de Pesquisas em Mandioca e Fruticultura da Embrapa, não se destacam na produção das chamadas tecnologias industriais - TI. O conhecimento de maior qualidade gerado nas instituições baianas está voltado para as áreas de saúde, ambiental, produção vegetal e animal e de recursos naturais, não se destacando na geração de produtos e processos, de TI, o que levaria a patentes.

$\mathrm{Na}$ esfera de P\&D, a Bahia conta com os centros de pesquisa do Senai/BA, o Centro de Tecnologia Industrial Pedro Lori - Cetind, o Centro Integrado de Manufatura e Tecnologia - CIMATEC e o Centro de Pesquisas e Desenvolvimen- 
to - Ceped, atualmente vinculado à Universidade do Estado da Bahia. O Cimatec tem, em princípio, competência para toda indústria e sua principal atuação está direcionada para as cadeias produtivas formadas pelos setores automotivo, metalmecânico, eletroeletrônico e transformação de plástico. Também pode atuar em outros segmentos da indústria, como os setores de calçados, confecçóes, alimentos e bebidas, petróleo e petroquímica. O Cetind, por sua vez, tem concentrado esforços para atender às indústrias de processos químicos e petroquímicos, expandindo atualmente seu foco para a indústria de processos contínuos e as do setor de telecomunicaçóes. Já o Ceped tem uma história de atuação em um amplo leque temático, mas, no momento, encontra-se esvaziado, tendo-se convertido, praticamente, em uma central de análises laboratoriais e abriga uma incubadora de empresas que necessariamente não podem ser definidas como de base tecnológica.

Segundo Ribeiro (2004b), a percepção que estes centros têm da sua importância no processo de inovação não é clara, sendo que a mesma é confundida com apoiar a indústria e não de realizar pesquisa. Para a autora, o Cimatec e o Cetind atuam predominantemente na prestação de serviços técnicos e tecnológicos e também educacionais. Ambos possuem uma boa infraestrutura de apoio, como laboratórios com tecnologias de suporte às necessidades industriais.

A rigor, pode-se afirmar que o fato de a ciência baiana ser periférica, o que sugere a breve análise sobre o perfil da pesquisa básica e sobre a P\&D, compromete não somente a própria produção científica stricto sensu, mas também a capacidade de interação com o setor produtivo visando a constituição de um verdadeiro sistema local de inovação com seus vários hábitats. Em termos rigorosos, de acordo com Corder e Filho (2004), não se pode afirmar que na Bahia exista um sistema de inovações. Malgrado se reconheça o esforço realizado por parte do governo e do próprio sistema Fieb para criar condições que estimulem e favoreçam o processo de inovação na Bahia, entre elas as recentes ações na área de CT\&I, como a criação da Fapesb em 2001 e da Secti em 2003, que coordenam intervençôes com vistas ao fortalecimento do sistema de inovação local, muito ainda há por se fazer. Convém, concluindo, salientar que o conjunto de mudanças necessárias depende sobretudo de vontade política, de compromissos dos atores envolvidos e de valores institucionais, como a colaboração e a confiança, colocando-se, todas elas, no campo da cultura de Ciência e Tecnologia. 


\section{Referências bibliográficas}

BAIARDI, A. Contribuições para a reorganização institucional do sistema estadual de C\&T. In: $15^{\circ}$ ENANPAD. Anais... Salvador, 1991.

. A competência na gestão de C\&T: o crescimento da Fundação Instituto Tecnológico de Pernambuco, ITEP, em plena crise. In: 16 ENANPAD. Anais... Canela-RS, 1992.

. Sociedade e estado no apoio à ciência e à tecnologia: uma análise histórica. São Paulo: Hucitec, 1996.

. Ciência, tecnologia e a competitividade da agricultura e da agroindústria regionais. Cruz das Almas: Embrapa, Documentos CNPMF 83, 1998.

. O papel do Imperial Instituto Bahiano de Agricultura na formação da comunidade de ciências agrárias do Brasil. Primeiro Congresso Luso-Brasileiro de História da Ciência e da Técnica, 2000. Évora: Editora da Universidade de Évora, 2001.

. O Imperial Instituto Bahiano de Agricultura e as mudanças na agricultura e na agroindústria da Bahia na segunda metade do séc. XIX. In: III CONGRESSO BRASILEIRO DE HISTÓRIA ECONÔMICA, 1999. Anais... Curitiba, 1999.

BAIARDI, A.; CHIAPETTI, J. O ambiente como fator de diferenciação em incubadoras de empresa de base tecnológica. Recitec, v. 3, n. 2, p. 190-294, 1999.

BAIARDI, A.; BASTOS, C. A propensão a inovar como manifestação cultural do empresariado regional. In: X SEMINÁRIO DE MODERNIZAÇÃO TECNOLÓGICA E PERIFÉRICA, 2007. Anais... Recife: Fundação Joaquim Nabuco, v. 1, 2007, p. 87-103.

BAIARDI, A.; VIEIRA dos SANTOS, A. A ciência e sua institucionalização na Bahia. Salvador: Instituto Rômulo Almeida de Altos Estudos, 2010.

CASSIOLATO, J. E. et al. Experiência e perspectivas da política brasileira de ciência e tecnologia. In: HERRERA, A. et al. Ciência, tecnologia e desenvolvimento 2. Brasília: Uneco/ CNPq, 1983.

DONADIO, L. Ciência e tecnologia: políticas institucionais. In: MARCOVITCH, J. (Org). Administração em Ciência e Tecnologia. Rio de Janeiro: Finep/ Edgard Blücher, 1983.

FERRARI, A. F.; VITAL BRASIL, E. A experiência brasileira de valorização da pesquisa: a propriedade industrial no Brasil. In: GOVERNO DO ESTADDO DE SĀO PAULO. Seminário internacional da invenção à inovação tecnológica: mecanismos de ação. São Paulo: Sedai, 1978. 
FIÚZA, S. Apontamentos históricos sobre a Escola Agrícola da Bahia. In: FIÚZA, S. (Org.). A Escola Agrícola da Bahia. Salvador: Typographia do Commercio, 1934.

LUNDWALL, B. A. Innovation as an interactive process: from user-producer interaction to the national system of innovation. In: DOSI, G. et al. Technical change and economic theory. London: Pinter Publishers, 1988.

MOTOYAMA S. et al. Novas tecnologias e desenvolvimento industrial brasileiro. In: MOTOYAMA S. Tecnologia e industrialização no Brasil. São Paulo: Editora Unesp, 1994.

NUNES, J. A. C. Os centros de P\&D e sua inserção no Programa Nacional de Capacitação Tecnológica. Rio de Janeiro: Coppe/UFRJ, 1990. Mimeo.

. A descentralização das políticas públicas de C\&T: o caso da Bahia, 1983-1992.

Dissertação (Mestrado). Rio de Janeiro: Coppe/UFRJ, 1993.

OCDE. Science, croissance et société: une perspective nouvelle. Brooks (coord.) Paris: Publications de l' OCDE, 1971.

RIBEIRO, M. T. F. Bases para a construção de políticas de ciência, tecnologia e inovações: uma proposta para o Estado da Bahia. In: XXIII SIMPÓSIO DE GESTÃO DA INOVAÇÃO TECNOLÓGICA. Curitiba: PGT/USP, $2004 a$.

O papel dos centros de pesquisa do Senai/BA na consolidação do sistema regional de inovação. In: XXIII SIMPÓSIO DE GESTÃO DA INOVAÇÃO TECNOLÓGICA. Curitiba: PGT/USP, $2004 b$.

SCHMOOKLER, J. Invention and economic growth. Cambridge: Harvard University Press, 1966.

Fuentes económicas de la actividad inventiva. In: ROSENBERG, N. Economia del cambio tecnológico. México: Fondo de Cultura Económica, 1979.

SCHWARTZMAN, S. Formação da comunidade cientifica no Brasil. Rio de Janeiro: Cia Editora Nacional/Finep, 1979.

(Coord.). Science and technology in Brazil: a new policy for a global world. Rio de Janeiro: Editora da FGV, 1995.

SUZIGAN, W.; ALBUQUERQUE, E. The underestimated role of universities for development: notes on historical roots of brazilian system of innovation. In: XVth WORLD ECONOMIC HISTORY CONGRESS, Utrecht, The Netherlands. August 3-7, 2009. 
